\title{
A ORIGEM DO CONCEITO DE PATOLOGIA SOCIAL NA OBRA DE AXEL HONNETH E SUAS CONTRIBUIÇÕES PARA A PSICOLOGIA
}

\author{
Matheus Rios Silva Santos ${ }^{1}$ e Carlos César Barros ${ }^{2}$ \\ 1. Bolsista FAPESB, Graduando em Psicologia, Universidade Estadual de Feira de Santana, e-mail: \\ matheusrssantos@gmail.com \\ 2. Orientador, Departamento de Ciências Humanas e Filosofia, Universidade Estadual de Feira de Santana, e-mail: \\ carlosbarros@uefs.br
}

PALAVRAS-CHAVE: Patologia Social; Axel Honneth; Psicologia

\section{INTRODUÇÃO}

Não é recente o diagnóstico de que a sociedade capitalista da modernidade tem enfrentado uma crise de valores. A fim de entender as causas, os desdobramentos e consequências dessa crise, Axel Honneth, atual diretor da Escola de Frankfurt, tem desenvolvido por mais de 30 anos estudos relacionados ao tema da Patologia Social. Nesse sentido, esse texto objetiva compartilhar o conhecimento que foi construído através da pesquisa "A origem do conceito de Patologia Social na obra de Axel Honneth e suas contribuições para a Psicologia", realizada entre os anos de 2015 e 2016. Essa pesquisa visou compreender a genealogia do conceito de Patologia Social nos escritos de Honneth, conhecer os autores que contribuíram para a formulação desse conceito, elaborar uma relação entre normatividade ética e Patologia Social bem como apontar um possível diálogo entre o tema da Patologia Social e a Psicologia do Reconhecimento.

Nossa investigação desponta como um importante instrumento de embasamento para discussões quanto às questões que impedem os sujeitos de alcançarem uma qualidade de vida ideal, ou para utilizar a expressão do próprio Honneth: os impedem de se autorrealizarem. Em tempos de crises, tais como vivem os brasileiros, é importante ter um olhar mais apurado para as causas de possíveis sofrimentos que acometem os indivíduos atualmente. Em última análise, compreender o que são as Patologias Sociais, como se desenvolveu esse conceito e qual a normatividade que nos possibilita diagnosticar uma Patologia Social é fundamental para compreender o caminho de uma racionalidade socialmente eficaz.

Ao final chegamos à conclusão de que podemos dividir os escritos de Axel Honneth sobre o conceito de Patologia Social em três grandes períodos: primeiro período, na década de 80 , diz respeito à busca das origens do conceito nas obras de Georg Lukács. O segundo período de reatualização, marcado por textos escritos nos anos 90, tem como foco as contribuições da Filosofia Social. Durante o terceiro período, marcado por textos escritos dos 2000 em diante, Honneth se concentra na investigação das obras dos escritores da Teoria Crítica em si mesma.

\section{MATERIAL E MÉTODOS OU METODOLOGIA}

O método utilizado foi a análise bibliográfica de materiais que nos ajudaram a traçar o desenvolvimento da definição de Patologia Social dentro da obra de Axel Honneth, assim como seus desdobramentos para a Psicologia do Reconhecimento. Por se tratar de uma pesquisa baseada essencialmente em investigação bibliográfica, o presente trabalho foi orientado pela metodologia científica desenvolvida por Marconi e Lakatos (2006), com as seguintes etapas de produção: identificação da bibliografia em catálogos de editoras, bibliotecas e periódicos na internet, análise de resumos e 
bibliografias das obras encontradas; localização das obras relevantes para a pesquisa; compilação; fichamento; análise e interpretação das mesmas.

\section{RESULTADOS E/OU DISCUSSÃO}

O primeiro resultado obtido é relativo à importância dos escritos de Georg Lukács como marco inicial para o desenvolvimento do conceito de patologia social na obra de Honneth. Chegamos a essa conclusão após analisar o texto "A Fragmented World: On the Implicit Relevance of Lukács Early Work" (1986). Pode-se afirmar que os escritos de Lukács funcionaram como um ponto de partida para as investigações de Honneth sobre o tema das Patologias Sociais. Nesse sentido, é possível inserir esse texto como pertencente à primeira fase de investigação do conceito. Outras importantes contribuições de Lukács foram o diagnóstico das três regiões de possível falta de desenvolvimento social, o desenvolvimento do ideal de sociedade intacta, o diagnóstico da crise na estrutura das relações sociais de reconhecimento, o destaque para a importância da comunicação nas relações sociais e, por fim, sua própria teoria, ao ser considerada por Honneth o maior legado deixado por Lukács uma vez que ela tem o poder de funcionar como um "instrumento sismográfico" para a teoria crítica da sociedade.

A segunda conclusão é que a tradição da Filosofia Social exerceu uma grande influência tanto para os primeiros delineamentos com Rousseau como para a forma de se conceber as Patologias Sociais na modernidade (Arendt e Taylor). Através da filosofia social, é possível elencar os autores que mais contribuíram para a formulação do conceito tais como: Rousseau, Hegel, Marx, Plessner, Nietzsche, Hannah Arendt e Charles Taylor. Para chegar a essa conclusão, o texto escrito nos anos 90: "Patologías de lo social: Tradición y actualidad de la filosofía social" (2011), com suas três longas seções, foi fundamental. Esse texto marca a segunda fase de reatualização do conceito de Patologia Social realizada por Honneth.

Ainda nessa fase, ganham destaque os escritos de Hegel sobre o sofrimento de indeterminação. Com base nas análises do texto " $O$ vínculo entre teoria da justiça $e$ diagnóstico de época" (2007), percebemos a importância que Honneth atribui à teoria da eticidade para a superação das Patologias Sociais. Honneth aponta que, de acordo com a teoria de Hegel, a "libertação" dos comportamentos patológicos que os sujeitos apresentam perpassaria pela eticidade. Alcançada essa libertação, os sujeitos acessariam as condições comunicativas, estariam mais próximos de alcançarem a justiça através da teoria da intersubjetividade e se libertariam das Patologias Sociais.

A terceira fase é o período em que Honneth busca justamente o legado da Teoria Crítica para o tema das Patologias Sociais. Com base na leitura do texto "Uma Patologia Social da Razão: Sobre o legado intelectual da Teoria Crítica" (2008) podemos inferir que ele está inserido nessa fase. O objetivo de Honneth de manter a Teoria Crítica frutífera a partir da reatualização desse tema justifica a preocupação dele em fazer o levantamento inicial e posterior dos textos de cada autor da Teoria Crítica sobre esse tema. Logra destaque também a grande influência que Hegel teve para esses autores e, consequentemente, a importância que era atribuída à razão para se pensar a Patologia Social. Conceitos como práxis racional, potencial racional, força racional, deformação histórica da razão estão presentes no texto e diretamente relacionados com a 
normatividade ética. De forma que, uma vida bem-sucedida estaria vinculada a uma razão socialmente eficaz, enquanto a deformação da razão geraria a patologia social. Por fim, é mister salientar a conclusão de Honneth quanto à importância do reconhecimento do núcleo comum das perspectivas valorativas para a autorrealização cooperativa. Ele conclui que o entendimento racional é uma forma de amalgamar a cooperação social e assim remediar a Patologia Social.

No que concerne à ideia de normatividade para o diagnóstico das Patologias Sociais, Honneth afirma que ainda é muito difícil, mesmo hoje, obter critérios concernentes à situação de como as relações comunicativas e a integração social se encontram nos dias atuais. Para ele, os trabalhos mais recentes de Charles Taylor, com a intenção de obter um esclarecimento conceitual da ideia de "autenticidade", aponta em direção de um diagnóstico filosófico relevante da era presente no qual o comunitarismo tem contribuído pouco para resolver a questão sobre em que medida podemos, nesse momento, falar de uma patologia da integração social. Vale ressaltar ainda a preferência de Honneth pela ideia de normatividade oferecida pelo escritor canadense ao defender uma justificação historicamente relativizada da ética para identificar as Patologias Sociais. Para Honneth, a única forma de conseguir informação sobre quais desenvolvimentos sociais têm que ser considerados como patologias sociais é recobrar hermeneuticamente o sentido dos valores éticos pelos quais se deixa guiar a modernidade e sua autocompreensão cultural.

Em relação ao diálogo entre o conceito de Patologia Social e a Psicologia, ganha destaque a importância que Honneth atribui ao atestar a necessidade da construção de uma teoria sócio-psicológica do sujeito que seja capaz de explicar porque os indivíduos que são condicionados por um modo particular de pensamento e de prática deveriam ser mais responsivos ao conteúdo racional da Teoria Crítica. Além disso, essa teoria sóciopsicológica precisa explicar de onde podem vir as forças subjetivas que poderiam oferecer a oportunidade para a transformação do conhecimento em práxis. Com o desenvolvimento da pesquisa, percebemos que Honneth, influenciado pela teoria da neurose de Freud, desenvolve a ideia de que o estresse do sofrimento impele em direção à cura por meio das mesmas capacidades racionais às quais a patologia impede de funcionar. À Psicologia cabe, portanto, se comprometer com a doutrina da eticidade de Hegel a fim de garantir aos sujeitos as condições comunicativas de liberdade, e conduzir à libertação das Patologias Sociais. O contrário disso é se comprometer com a racionalidade socialmente deficiente que já está posta, e permanecer no risco de se tornar, essa própria área do conhecimento, uma Patologia Social.

Por fim, percebe-se que a mudança com as abordagens sócio-teóricas que, em face de uma crescente desintegração social, falam de uma transição para uma época do "pós-moderno", tem levado Honneth a dar um pequeno passo adiante. Nesse sentido, muitos trabalhos que hoje estão interessados em um diagnóstico da época presente apontam indiretamente para uma condição de nossa sociedade que Honneth descreveria como uma crise na estrutura das relações sociais de reconhecimento. Assumidamente, a fim de ser capaz de fornecer a esta tese um grau maior de decisão teórica e plausibilidade empírica, isso vai, antes de tudo, exigir ainda mais da investigação com relação à dimensão com a qual nós estamos atualmente encarando um processo pelo 
qual os padrões de reconhecimento têm, até agora, sofrido uma desintegração irremediável.

\section{CONSIDERAÇÕES FINAIS}

Com base nos resultados que foram alcançados através da pesquisa, é possível inferir que a genealogia do conceito de Patologia Social na obra de Honneth é marcada por três grandes fases de reatualização do conceito. Podendo-se afirmar que Georg Lukács é o primeiro teórico a quem Honneth recorre para estudar o tema e que, portanto, pode ser considerado o precursor do tema na obra de Honneth marcando a primeira fase. Na segunda fase, tem-se as contribuições dos autores da filosofia social, com destaque para a filosofia do direito de Hegel que propõe a eticidade como meio de superar a Patologia Social. E na terceira fase, encontram-se as contribuições de Theodor Adorno, Hebert Marcuse, Jürgen Habermas e Max Horkheimer, todos autores da Escola de Frankfurt, sobre o tema.

Através dos resultados obtidos, compreende-se também a importância da Psicologia se comprometer com o desenvolvimento de conhecimentos e teorias que estejam comprometidos tanto com a teoria da eticidade de Hegel quanto com uma racionalidade socialmente eficaz. Isso implica dizer que a Psicologia do Reconhecimento que se proponha a libertar os sujeitos dos seus comportamentos patológicos precisa garantir aos sujeitos acesso às esferas comunicativas a fim de que esses possam chegar igualmente à realização de suas autonomias.

\section{REFERÊNCIAS}

HONNETH, Axel. Disrespect: the normative foundations of critical theory. Cambridge: Polity Press, 2007a.

Luta por reconhecimento: a gramática moral dos conflitos sociais. São Paulo: Ed. 34, 2003.

Pathologies of reason: on the legacy of critical theory. New York: Columbia University Press, 2009.

The fragmented world of the social: essays in social and political philosophy. State University of New York Press, 1995

Uma patologia social da razão: sobre o legado intelectual da teoria crítica. In: RUSH, Fred. (Org.). Teoria crítica. Aparecida, SP: Ideias \& Letras, 2008. p. 389415

Social action and human nature. Cambridge University Press, 1988.

La sociedad del desprecio. Madrid: Trotta, 2011.

Sofrimento de Indeterminação: uma reatualização da Filosofia do Direito

de Hegel. Tradução de Rúrion Soares Melo. São Paulo: Editora Singular/Esfera Pública, 2007.

MARCONI, M.A.; LAKATOS, E.M. Metodologia do trabalho científico: procedimentos básicos, pesquisa bibliográfica, projeto e relatório, publicações e trabalhos científicos. $6^{\text {a }}$. Ed. São Paulo: Atlas, 2006. 